\title{
Experimental characterization of water flow through smooth rectangular microchannels
}

\author{
R. Baviere ${ }^{\text {a) }}$ \\ Centre de Recherches sur les Très Basses Températures (CNRS), B.P. 166, 38042 Grenoble Cedex 09, \\ France and Laboratoire des Ecoulements Géophysiques et Industriels (CNRS-UJF-INPG), B.P. 53, \\ 38041 Grenoble Cedex 09, France \\ F. Ayela \\ Centre de Recherches sur les Très Basses Températures, B.P. 166, 38042 Grenoble Cedex 09, France \\ S. Le Person and M. Favre-Marinet \\ Laboratoire des Ecoulements Géophysiques et Industriels, B.P. 53, 38041 Grenoble Cedex 09, France
}

(Received 15 October 2004; accepted 20 July 2005; published online 26 September 2005)

\begin{abstract}
This article presents experimental results obtained in water flows through smooth rectangular microchannels. The experimental setup used in the present study enabled the investigation of both very small length scales $(21-4.5 \mu \mathrm{m})$ and a wide range of Reynolds numbers $(0.1-300)$. The evolution of the friction coefficient was inferred from pressure drop versus flow-rate measurements for two types of water with different electrical conductivities. The channels were made of a silicon engraved substrate anodically bonded to a Pyrex cover. In these structures, pressure losses were measured internally with micromachined $\mathrm{C}_{\mathrm{u}}-\mathrm{N}_{\mathrm{i}}$ strain gauges. When compared to macroscale correlations, the results demonstrate that in smooth silicon-Pyrex microchannels larger than $4 \mu \mathrm{m}$ in height, the friction law is correctly predicted by the Navier-Stokes equations with the classical no-slip boundary conditions, regardless of the water electrical conductivity $\left(>0.1 \mu \mathrm{S} \mathrm{cm}^{-1}\right)$.

(C) 2005 American Institute of Physics. [DOI: 10.1063/1.2039667]
\end{abstract}

Several fundamental studies, over the last 15 years, have explored the basic characteristics of momentum and heat transfer for liquids flowing in microstructures. This research has been motivated by their future use in many industrial applications. The previously published works related to this paper are based on pressure drop versus flow-rate measurements performed in microchannels, both in the laminar regime $^{1-7}$ and in the transitional regime. ${ }^{8-13}$ These experimental studies have questioned the validity of using the classical flow theory for liquids in ducts of hydraulic diameter smaller than $500 \mu \mathrm{m}$. Up to the last two or three years, the published literature showed very dispersed results on the friction coefficient in microchannels (see review papers ${ }^{2,13,14}$ ). These discrepancies were interpreted by some investigators as the result of early transition to turbulence or electrokinetics interactions at the solid-liquid interface. However, these hypotheses do not match all the published results and the great variety of trends observed remains difficult to interpret. The deviations from the classical theory may also have been, in part, caused by erroneous comparisons between results obtained in smooth and rough microducts. ${ }^{6,8,9,12,15}$ This paper is focused on the hydrodynamics of liquid flows in smooth wall microchannels (relative roughness $<0.5 \%$ ).

In duct flows, pressure losses are evaluated in terms of the Fanning friction factor

${ }^{a)}$ Electronic mail: roland.baviere@grenoble.cnrs.fr

$$
f=\tau_{w} /\left(1 / 2 \rho U^{2}\right),
$$

where the wall shear stress $\tau_{w}$ is deduced from pressure loss measurements, $\rho$ is the density, and $U$ is the fluid bulk velocity. For the fully developed laminar regime in conventional ducts, the product $f \operatorname{Re}$ (Reynolds number Re of the flow based on $U$ and the hydraulic diameter $D_{h}$ ) is a constant referred to as the Poiseuille number Po, which only depends on the cross-sectional geometry of the duct. ${ }^{16}$ Table I summarizes the available friction coefficient measurements for laminar liquid flows in smooth microducts. These works are displayed in decreasing order of the internal length scale (smallest dimension of the cross-sectional geometry). Much work has been done on flows in smooth microducts with an inner scale larger than $30 \mu \mathrm{m}$. Of special interest are the most recent studies which, for the greater part, support the classical flow theory. ${ }^{3,6,7,11-13}$ A noticeable exception stands with the experimental investigation of Brutin and Tadrist. ${ }^{4}$ The authors reported up to a $27 \%$ excess in Po for distilled and tap water flows in fused silica microtubes of diameters ranging from 530 to $50 \mu \mathrm{m}$ and interpreted this deviation as the result of electrokinetic effects. Subsequently, Phares and Smedley ${ }^{6}$ calculated that Brutin and Tadrist's ${ }^{4}$ observations were not consistent with the conventional model of the electroviscous effect. Their conclusion was supported by pressure drop measurements performed with water samples of different ionic concentrations flowing in smooth polyimide microtubes from 152 to $119 \mu \mathrm{m}$. According to a recent comment of Brutin and Tadrist, ${ }^{17}$ additional charge-related surface interactions may account for the observed behavior.

Fewer experiments have been performed for an inner 
TABLE I. Summary of available friction coefficient measurements for laminar liquid flows in smooth microducts:

\begin{tabular}{|c|c|c|c|c|}
\hline Authors & Dimensions $(\mu \mathrm{m})$ & Fluid & Duct & Observations \\
\hline Pfund et al. (Ref. 10) & $521,263,128$ & Water & $\begin{array}{l}\text { Polycarbonate/polyimide } \\
\text { microchannels }\end{array}$ & $+10 \%$ to $+20 \%$ in $\mathrm{Po}$ \\
\hline Phares et al. (Ref. 6) & 152,119 & $\begin{array}{l}\text { De-ionized and tap water, } \\
\text { saline solution }\end{array}$ & Polyimide microtubes & $\begin{array}{l}\text { Agreement with classical flow } \\
\text { theory }\end{array}$ \\
\hline Gao et al. (Ref. 11) & $500,400 \ldots, 100$ & Demineralized water & Bronze microchannels & $\begin{array}{l}\text { Agreement with classical flow } \\
\text { theory }\end{array}$ \\
\hline Li et al. (Ref. 12) & $205-80$ & De-ionized water & $\begin{array}{l}\text { Glass and silicon } \\
\text { microtubes }\end{array}$ & $\begin{array}{c}\text { Agreement with classical flow } \\
\text { theory }\end{array}$ \\
\hline Brutin et al. (Ref. 4) & $530-50$ & Distilled and tap water & Fused silica microtubes & $\begin{array}{l}0 \% \text { to }+27 \% \text { in Po depending } \\
\text { on the fluid's ionic properties }\end{array}$ \\
\hline Sharp et al. (Ref. 13) & $247-50$ & $\begin{array}{l}\text { Deionized water, 1-propanol, } \\
\text { glycerol solution }\end{array}$ & Glass microtubes & Agreement with classical flow theory \\
\hline Kohl et al. (Ref. 7) & $98-24$ & Water & Silicon microchannels & Agreement with classical flow theory \\
\hline Judy et al. (Ref. 3) & $150-20$ & $\begin{array}{l}\text { Distilled water, methanol, } \\
\text { isopropanol }\end{array}$ & Fused silica microtubes & $\begin{array}{l}\text { Agreement with classical flow } \\
\text { theory }\end{array}$ \\
\hline Papautsky et al. (Ref. 2) & 30,20 & Water & Nickel micropipettes & $+10 \%$ to $+20 \%$ in $\mathrm{Po}$ \\
\hline Ren et al. (Ref. 5) & $40.5,28.2,14.1$ & $\begin{array}{l}\text { De-ionized water and } \mathrm{KCl} \\
\text { solutions }\end{array}$ & Silicon microchannels & $+0 \%$ to $+20 \%$ in $\mathrm{Po}$ \\
\hline Pfahler et al. (Ref. 1) & $53,1.7,0.8$ & N-propanol & $\begin{array}{l}\text { Silicon-Pyrex } \\
\text { microchannels }\end{array}$ & $-50 \%$ to $+500 \%$ in Po \\
\hline
\end{tabular}

scale smaller than $30 \mu \mathrm{m}$ and their results are rather conflicting. Both reduction ${ }^{1}$ and increase ${ }^{1,2,5}$ from the conventional value have been reported for the measured Poiseuille number. A physical phenomenon that could possibly influence pressure-driven liquid flows in microstructures is the presence of an electrical double layer (EDL) at a solid/liquid interface. The theory ${ }^{18,19}$ shows that the interaction between pressure-driven liquid flows and electrostatic forces in the EDL leads to an apparent increased fluid viscosity. A necessary condition for the occurrence of a significant electroviscous effect is a low electrokinetic radius $\left(r_{\text {elec }}\right.$ $=D_{h} / \lambda_{D}, \lambda_{D}$ =liquid Debye length). Since the Debye length of a liquid increases when its ionic concentration decreases, the above condition corresponds to dilute ionic solutions in narrow microducts. Recently, Phares and Smedley ${ }^{6}$ calculated that the electroviscous effect may become significant for de-ionized water flows in microducts smaller than $50 \mu \mathrm{m}$. In particular, flows of de-ionized water in tubes $4 \mu \mathrm{m}$ in diameter are expected to exhibit an apparent viscosity more than two times larger than the fluid bulk viscosity. To our knowledge, only Ren et al. ${ }^{5}$ have experimentally detected an electroviscous effect for ultrafiltered de-ionized water flowing in a 14.1- $\mu$ m-deep microchannel. However, their results have not been confirmed and should therefore be considered cautiously. It is clear from the above review that refined measurements of Poiseuille numbers are still helpful to have a better insight in microscale flows and the related EDL effects.

We present results obtained in well-controlled experiments that allow varying the ionic composition of the fluid and consequently, the electrokinetic radius of the flow in microchannels of very small size (21-4.5 $\mu \mathrm{m}$ in height). The experiments were conducted in large aspect ratio microchannels, made of silicon and Pyrex, and equipped with two local micromachined pressure probes. ${ }^{20}$ The advantage upon inlet/ outlet pressure measurements is to avoid making assumptions on the minor losses that occur at the channel inlet and outlet. To our knowledge, there has been only one recently published work $^{7}$ on internal measurements in such small structures. The manufacturing of these devices consists of four main steps:

(i) Two square $\left(3 \times 3 \mathrm{~mm}^{2}\right)$ deflecting membranes of about $100 \mu \mathrm{m}$ in thickness are chemically etched with $\mathrm{KOH}$ at $80{ }^{\circ} \mathrm{C}$ on the top face of a $15 \times 20 \mathrm{~mm}^{2}$ silicon substrate, double polished and coated with a 100-nm silicon nitride $\left(\mathrm{Si}_{3} \mathrm{~N}_{4}\right)$ layer.

(ii) A 400-nm aluminum layer is then evaporated on the top face; a microchannel, inlet and outlet sumps, and two $30-\mu \mathrm{m}$ wide pressure taps connecting the membranes to the microchannel are lithographed together in the aluminum layer. These patterns are then reactively ion etched through the aluminum mask.

(iii) Aluminum and $\mathrm{Si}_{3} \mathrm{~N}_{4}$ are subsequently removed from the top face of the sample. Figure 1 shows a scanning electron microscopy (SEM) view of a sample at this step of the fabrication process. After that, a Pyrex cover is anodically bonded to the silicon wafer in order to cap the channel.

(iv) $\mathrm{Cu}-\mathrm{Ni}$ strain gauges, 350-nm in thickness, forming a Wheatstone bridge are sputtered and lithographed on the back side of the deflecting membranes still coated with $\mathrm{Si}_{3} \mathrm{~N}_{4}$.

Details on the microfabrication principles, the characterization of the integrated pressure transducers and the calibration procedures can be found in Ref. 20. The microdevices were included to an experimental loop composed of a high- 


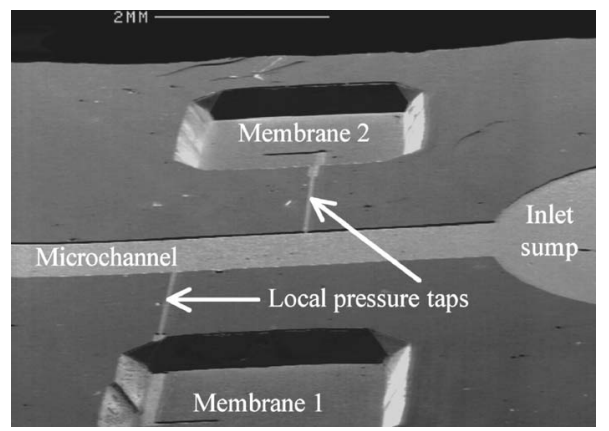

FIG. 1. Micrograph of a silicon substrate (microchannel $n^{\circ} 1$ connected to a pair of deflecting membranes). Dimensions in Table II.

pressure expansion tank (up to 25 bars), a 0.45 - $\mu \mathrm{m}$ filter, a Pt 100 temperature probe for determining the outlet temperature of the fluid, two lock-in amplifiers (NF Electronic Instruments, $5610 \mathrm{~B}$ ), a high precision pressure transmitter (Keller-33×, 30 bars, 0.025\%) used for the strain gauges calibration procedure, and a high-precision balance (KernGS, $410 \mathrm{~g}, 0.001 \mathrm{~g}$ ). The accuracy of the micromachined strain gauges was estimated to be $\pm 7.510^{-3}$ bar. The flow rates were measured by using the classical weighing method and ranged from $2 \times 10^{-6} 1 \mathrm{~min}^{-1}$ to $0.011 \mathrm{~min}^{-1}$. The measuring instruments were all connected to a PC microcomputer. The microchannel height was measured in the following two ways: Firstly, a Tencor profilometer determined the engraved depth of the silicon substrate before bonding the Pyrex cap. For each sample, the measurements were done along four transversal lines placed in between the two local pressure taps. Secondly, the microchannels were analyzed by postmortem observations of their transverse cross section. The silicon-Pyrex ensemble was cleaved, sputter-coated with a few nanometers layer of gold, and inspected in a scanning electron microscope (Fig. 2). This verification ensured that the channel geometry was not affected by the anodic bonding operation. Both methods yielded similar results. The Tencor profilometer was also used to examine the surface finish of the silicon engraved stripes and the Pyrex substrate. The roughness height denoted $k$ was found to be less than $5 \mathrm{~nm}$ for the Pyrex substrate. It was more variable for the silicon engraved walls: the scans revealed basic irregularities of amplitude smaller than $5 \mathrm{~nm}$ and isolated roughness elements of $30 \mathrm{~nm}$ in height. The active channel walls were dielectric and probably hydrophilic during the measurements. In fact, the flattening of water drops deposited on both substrates prior to

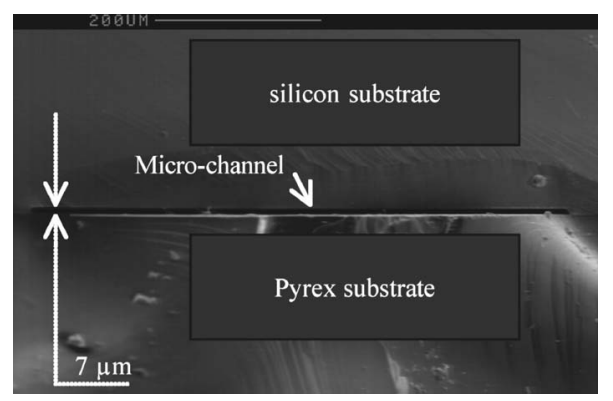

FIG. 2. Cross-sectional scanning electron microscope view of a siliconPyrex microchannel.
TABLE II. Geometrical characteristics of the smooth silicon-Pyrex microchannels $(k<0.05 \mu \mathrm{m})$.

\begin{tabular}{cccccc}
\hline \hline$n^{\circ}$ & $h(\mu \mathrm{m})$ & $L(\mathrm{~mm})$ & $L_{p}(\mathrm{~mm})$ & $w(\mathrm{~mm})$ & $d \mathrm{Po} / \mathrm{Po}$ \\
\hline 1 & $20.5( \pm 0.1)$ & 6 & 1.5 & 1 & $\pm 7.7 \%$ \\
2 & $14.3( \pm 0.1)$ & 6 & 1.5 & 1 & $\pm 8.3 \%$ \\
3 & $7.5( \pm 0.2)$ & 6 & 1.5 & 3 & $\pm 14 \%$ \\
4 & $4.58( \pm 0.05)$ & 2 & 0.5 & 0.215 & $\pm 9.9 \%$ \\
\hline \hline
\end{tabular}

the anodic bonding operation was clearly observed. This is most probably due to the previous immersion of the substrates in nitric acid, which is known to result in superficial coating by a thin layer of hydrophilic $\mathrm{SiO}_{2}$. Table II gives a summary of the geometrical characteristics of the different microchannels tested in this work. $h$ is the distance between the Pyrex wall and the silicon wall. $L, L_{p}$ and $w$ are, respectively, the total channel length, the distance between the two local pressure taps and the width of the channel. The working fluid was stored in the Butyl II-R vessel of an expansion tank. The vessel was entirely filled with water and air was vacuumed out of the whole fluid loop before running the experiments. This prevented gas from being trapped in the pressure probe cavities. To measure very low flow-rates, the outlet reservoir was covered with a finely pierced latex sheet and, in addition, a film of oil sheltered the free surface to limit water evaporation. The very small evaporation rate $\left(10^{-7} 1 \mathrm{~min}^{-1}\right)$ was taken into account in the flow-rate determination.

The friction coefficient was calculated from the measured pressure drop $\Delta P$ between the two local pressure taps:

$$
f=\Delta P D_{h} / 2 \rho U^{2} L_{p} \text {. }
$$

The location of the first pressure tap $x_{1}$ was chosen to be far from the channel entrance $\left[x_{1}^{+}=\left(x_{1} / D_{h}\right)(1 / \mathrm{Re})>0.2\right.$ in all of the experiments]. Therefore, the results were compared to the fully developed laminar regime in conventional channels: ${ }^{16}$

$$
f=24 / \operatorname{Re} \text { or } \mathrm{Po}=f \operatorname{Re}=24 \text {. }
$$

The Po number was deduced from the measured quantities by

$$
\mathrm{Po}=2\left(\Delta P L_{p}\right) /\left(w h^{3} / q \nu\right),
$$

where $q$ stands for the mass flow rate and $\nu$ is the kinematic viscosity of the fluid. The physical properties of water were determined at the fluid outlet temperature. A careful analysis of the experimental uncertainties is critical for the determination of apparent deviation from the classical theory. The uncertainties associated with Po were estimated by using Eq. (4). It should be emphasized that the inaccuracy in the evaluation of $h$ is the major source of error in the determination of Po. The uncertainty on $\nu$ was $2 \%\left( \pm 1{ }^{\circ} \mathrm{C}\right.$ for the mean bulk temperature). The uncertainties on both the pressure losses and the mass flow-rate measurements depend on $\mathrm{Re}$ and reached $3 \%$ for the upper limit of the measuring range. However, more relevant values for the series of measurements were, respectively, $1.5 \%$ and $0.75 \%$. The uncertainties on the width and the length of the channel were both estimated at 


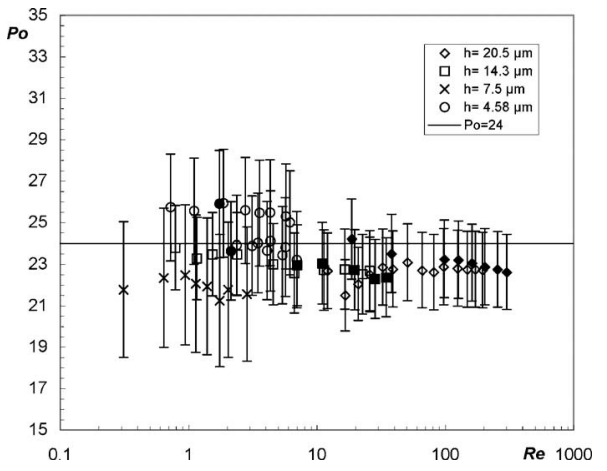

FIG. 3. Poiseuille number Po vs Re for smooth silicon-Pyrex microchannels $(h=20.5,14.3,7.5$, and $4.58 \mu \mathrm{m})$. Open symbols: water conductivity $<0.1 \mu \mathrm{S} \mathrm{cm}^{-1}$. Solid symbols: water conductivity $=70 \mu \mathrm{S} \mathrm{cm}^{-1}$. $\times$ : water conductivity $=7 \mu \mathrm{S} \mathrm{cm}^{-1}$.

$1 \%$. The global uncertainty on the Poiseuille number ranged from $\pm 7.7 \%$ to $\pm 14 \%$ for the microchannels $n^{\circ} 1-n^{\circ} 4$ (Table II). In order to detect a possible electroviscous effect, experiments were first conducted with de-ionized water (electrical conductivity of $<0.1 \mu \mathrm{S} \mathrm{cm}^{-1}$ ) then with a solution of tap water $(1 / 4)$ in de-ionized water (3/4) (electrical conductivity of $\left.70 \mu \mathrm{S} \mathrm{cm}^{-1}\right)$. An equivalent ion concentration $I(\mathrm{~mol} / \mathrm{l})$, can be deduced from these measurements using the ionic conductance of $\mathrm{Na}^{+}$and $\mathrm{Cl}^{-}$ions. This method yields $-\log ([I])>6.1$ for the de-ionized water and $-\log ([I])$ $=3.2$ for the dilute tap water. According to Phares and Smedley's calculations, ${ }^{6}$ significant electroviscous effects (more than $20 \%$ increase of the apparent viscosity) may arise in ducts of inner scale smaller than $10 \mu \mathrm{m}$ for water with a negative $\log$ of molarity larger than $6[-\log ([I])>6]$.

The results presented in Fig. 3 show that Po remains independent of $\mathrm{Re}$ at the small scales investigated in this work. Moreover, Fig. 3 clearly demonstrates that the electrical conductivity of water does not play a significant role on the characteristics of the flows studied here. A similar conclusion was drawn by Phares and Smedley ${ }^{6}$ but for microtubes larger than $150 \mu \mathrm{m}$ in diameter. On the other hand, the data presented in Fig. 3 differ from the results of Brutin and Tadrist ${ }^{4,17}$ obtained in microtubes from 530 to $50 \mu \mathrm{m}$ in diameter. A noticeable difference between their experimental facility and the present one is that these authors used highpressure gas to force water through the fluid loop. Considering the very long duration of their experimentations (" $21 \mathrm{~h}$ for a 33.4-mm-long 50- $\mu \mathrm{m}$ capillary" ${ }^{\prime 4}$ ), it is likely that the working fluid was saturated with gas. Due to the highpressure losses occurring in these flows, it is possible that the dissolved gas has expanded to form bubbles in the downstream part of the microtubes where the pressure becomes low, resulting in an artifical increase of the friction losses. In 2001, Ren et al. ${ }^{5}$ found a $20 \%$ increase in Po for de-ionized water flowing in a silicon microchannel $14.1 \mu \mathrm{m}$ in height compared to aqueous solutions of a higher ionic concentration. Figure 3 shows that we were not able to reproduce their results in silicon-Pyrex microchannels of similar or smaller heights. Differences in the measuring techniques are highly suspected to be responsible for such a discrepancy. ${ }^{6}$

The results of these experiments have proved that the friction factor is correctly predicted by the classical NavierStokes equations at the small scales investigated in this study. No scale effect was found for water flows in rectangular smooth microchannels of height ranging from 21 to $4.5 \mu \mathrm{m}$ and for Reynolds number varying between 0.1 and 300. In fact, the friction factors measured with two types of water are effectively quite similar. These results suggest that deviations from the conventional theory observed in other experiments with analogous conditions cannot be explained by the electroviscous effect. Moreover, it can be noted that the actual importance of the electroviscous effect is overestimated by Phares and Smedley's calculations ${ }^{6}$ for practical situations where de-ionized water flows in silicon-Pyrex microchannels.

This research was supported by the CNRS and the Rhône-Alpes region. The authors wish to thank Pierre Brosse-Maron for his help in the manufacture of the experimental apparatus.

${ }^{1}$ J. Pfahler, J. Harley, and H. Bau, "Liquid transport in micron and submicron channels," Sens. Actuators, A 21-23, 431 (1990).

${ }^{2}$ I. Papautsky, J. Brazzle, T. Ameel, and A. B. Frazier, "Laminar fluid behavior in microchannels using micropolar fluid theory," Sens. Actuators, A 73, 101 (1999).

${ }^{3}$ J. Judy, D. Maynes, and B.W. Webb, "Characterization of frictional pressure drop for liquid flows through microchannels," Int. J. Heat Mass Transfer 45, 3477 (2002).

${ }^{4}$ D. Brutin and L. Tadrist, "Experimental friction factor of a liquid flow in microtubes," Phys. Fluids 15, 653 (2003).

${ }^{5}$ L. Ren, W. Qu, and D. Li, "Interfacial electrokinetic effects on liquid flow in microchannels," Int. J. Heat Mass Transfer 44, 3125 (2001).

${ }^{6}$ D. J. Phares and G. T. Smedley, "A study of laminar flow of polar liquids through circular microtubes," Phys. Fluids 16, 1267 (2004).

${ }^{7}$ M. J. Kohl, S. I. Abdel-Khalik, S. M. Jeter, and D. L. Sadowski, "An experimental investigation of microchannel flow with internal pressure measurements," Int. J. Heat Mass Transfer 48, 1518 (2005).

${ }^{8}$ G. M. Mala and D. Li, "Flow characteristics of water in microtubes," Int. J. Heat Fluid Flow 20, 142 (1999).

${ }^{9}$ Q. Weilin, G. M. Mala, and D. Li, "Pressure-driven water flows in trapezoidal silicon microchannels," Int. J. Heat Mass Transfer 43, 353 (2000).

${ }^{10}$ D. Pfund, D. Rector, A. Shekarriz, A. Popescu, and J. Welty, "Pressure drop measurements in a microchannel," AIChE J. 46, 1496 (2000).

${ }^{11}$ P. Gao, S. Le Person, and M. Favre-Marinet, "Scale effects on hydrodynamics and heat transfer in two-dimensional mini and micro-channels," Int. J. Therm. Sci. 41, 1017 (2002).

${ }^{12}$ Z. X. Li, D. X. Du, and Z. Y. Guo, "Experimental study on flow characteristics of liquid in circular microtubes," Microscale Thermophys. Eng. 7, 253 (2003).

${ }^{13}$ K. V. Sharp and R. J. Adrian, "Transition from laminar to turbulent flow in liquid filled microtubes," Exp. Fluids 36, 741 (2004).

${ }^{14}$ C. B. Sobhan and S. V. Garimella, "A comparative analysis of studies on heat transfer and fluid flow in microchannels," Microscale Thermophys. Eng. 5, 293 (2001).

${ }^{15}$ R. Baviere, F. Ayela, S. Le Person, and M. Favre-Marinet, "An experimental study of water flow in smooth and rough rectangular microchannels," Second International Conference on Microchannels and Minichannels, Rochester, June 2004, edited by S. G. Kandlikar (ASME, New York, 2004), pp. 221-228.

${ }^{16}$ F. M. White, Viscous Fluid Flow, 2nd ed. (McGraw-Hill, New York, 1991).

${ }^{17}$ D. Brutin and L. Tadrist, "Comment on 'A study of laminar flow of polar liquids through circular microtubes'," Phys. Fluids 17, 019101 (2005).

${ }^{18}$ D. Burgreen and F. R. Nakache, "Electrokinetic flow in ultrafine capillary slits," J. Phys. Chem. 68, 1084 (1964).

${ }^{19}$ C. L. Rice and R. Whitehead, "Electrokinetic flow in a narrow cylindrical capillary," J. Phys. Chem. 69, 4017 (1965).

${ }^{20}$ R. Baviere, and F. Ayela, "Micromachined strain gauges for the determination of liquid flow friction coefficients in microchannels," Meas. Sci. Technol. 15, 377 (2004). 